\title{
Araştırma-Geliştirme Harcamaları Ekonomik Büyümenin Nedeni Mi? Türkiye Bilgi ve İletişim Teknolojileri Sektörü Örneği *
}

\author{
Bekir PAKDEMIRLİ1 \\ Özet
}

Ar-Ge harcamaları yenilikte, verimlilik artışında ve ekonomik büyümede rol alan önemli bir motordur. Ar-Ge harcamalarına gereken önemi veren ülkeler, bilim ve teknoloji alanında ilerlemiş ve daha rekabetçi hale gelmişlerdir. Bu çalışmada, Türkiye'de Bilgi ve İletişim Teknolojileri Sektörü Ar-Ge harcamalarının gelişimi hakkında bilgi verilmiş, Ar-Ge harcamaları ve ekonomik büyüme ilişkisi Granger nedensellik testi yardımıla 2003-2017 yılları arası veriler kullanılarak analiz edilmiştir. Dolayısıyla, Bilgi ve İletişim Teknolojileri sektörünün, sürdürülebilir ekonomik büyüme için önemi ortaya konulmuştur. Çalışmanın sonuçları, BITT Ar-Ge harcamaları ve BİT sektörü hasılası arasında iki yönlü bir nedensellik bulgusunu ortaya koymaktadır. Diğer bir deyişle, Ar-Ge harcamaları BİT sektörü hasılasını, BİT hasılası da Ar-Ge harcamalarını olumlu olarak etkilemektedir.

Anahtar kelimeler: Ar-Ge, BİT, Granger nedensellik, Türkiye Jel Kodu: 011, 03

\section{Are Research and Development Expenditures the Cause of Economic Growth? Evidence from Information and Communication Technology Sector of Turkey}

\begin{abstract}
$R \& D$ expenditures is an important engine that plays a role in innovation, productivity and economic growth. Countries that attach importance to $R \& D$ spending have advanced in science and technology and have become more competitive. In this study, information is given about the R\&D expenditures development of Information and Communication Technologies Sector in Turkey and the relationship between R\&D expenditures and economic growth is analysed with Granger causality test using data from 2003-2017. Therefore, the importance of the Information and Communication Technologies sector for sustainable economic growth is demonstrated. The results of the study reveal a bidirectional causality between ICT R\&D expenditures and ICT sector revenue. In other words, R\&D expenditures positively affect the ICT sector revenue, and ICT revenue positively affects $R \& D$ expenditures.
\end{abstract}

Keywords: R\&D, ICT, Granger causality, Turkey

Jel Codes: 011, 03

\section{GİRIş}

Ülkeler için sürdürülebilir bir ekonomik büyümenin sağlanması yoğun rekabetçi biçimde küreselleşen dünya ekonomisinde büyük önem arz etmektedir. Ülkelerin ekonomik güçlerinin sürekli olması yeniliklerin sayısına, yeniliklerin sayısı ise ArGe faaliyetlerine gereken önemin verilmesine bağlıdır (Kocamış ve Güngör, 2014).
Günümüzde, gelişmiş ülkeler teknolojisi de gelişmiş olan ülkeler olarak görülmektedir. Ekonomik büyüme, teknolojik gelişmelerle el ele yürümekte ve bu gelişmeler Ar-Ge harcamalarının nedeni olarak ortaya çıkmaktadır (Kocamış ve Güngör, 2014).

Ar-Ge harcamalarına önem veren ekonomiler, bilim ve teknoloji alanında ilerlemiş ve daha rekabetçi hale gelmişlerdir. Türkiye Ar-Ge

\footnotetext{
* Bu makalede bilimsel araştırma ve yayın etiği ilkelerine uyulmuştur. / In this article, the principles of scientific research and publication ethics were followed.

$\mathrm{Bu}$ makalenin ilk versiyonu UYSAD 2nd International Conference on Management and Social Sciences (20-22 Nisan 2019, Antalya, Türkiye) konferansında sözlü olarak sunulmuştur. Daha sonra çalışmanın başlığl, içeriği ve metodolojisi değiştirilerek ve genişletilerek çalışma güncellenmiştir.
}

ATIF ÖNERİ́i (APA): Pakdemirli, B. (2020). Araştırma-Geliştirme Harcamaları Ekonomik Büyümenin Nedeni Mi? Türkiye Bilgi ve İletişim Teknolojileri Sektörü Örneği. İzmir İktisat Dergisi. 35(1). 105-112. Doi: 10.24988/ije.202035108

${ }^{1}$ Dr., T.C. Tarım ve Orman Bakanlığı, Ankara EMAIL: bekir@pakdemirli.com ORCID: 0000-0002-0336-0613 


\section{B. PAKDEMIRL $\dot{I}$}

harcamalarında gelişmiş dünya ülkelerinin gerisinde yer almaktadır. Dünyada 2015 yılında yapılan Ar-Ge harcamalarının GSYİH'ye oranı ülkeler bazında Şekil 1'de görülmektedir. İsrail, İsviçre, İsveç, Almanya, ABD gibi ülkeler ortalama \%3 Ar-Ge harcaması yapmakta, OECD ülkeleri ortalaması yaklaşık \%2,5, 28 Avrupa ülkesinin ortalaması ise yaklașık \%2 seviyesindedir. Türkiye ise Ar-Ge harcamalarında GSYIH oranında \%1'in altında kalmaktadır.

Şekil 1. Dünyada Ar-Ge Harcamaları/GSYİH (\%)

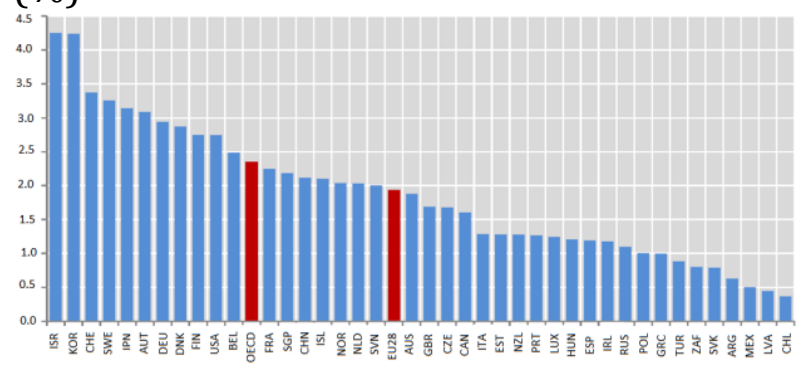

Kaynak: OECD, 2017.

Bilgi ve İletişim Teknolojileri (BİT) sektörü, özellikle on yıldan uzun bir süredir ekonomik değişimlerin merkezinde yer almaktadır. Bunun yanında son dünya ekonomik krizi sırasında dirençli bir sektör olduğunu kanıtlanmıştır. BİT sektörü teknolojik ilerleme, çıktı ve verimlilik artışına katkıda bulunur. BİT sektörünün etkileri, birkaç şekilde doğrudan üretim, istihdam veya verimlilik artışına katkısı ile ya da dolaylı olarak, örneğin ekonominin diğer bölümlerini etkileyen teknolojik bir değișim kaynağı olarak sıralanabilir (OECD, 2015). Şekil 2, BİT sektöründe şirketler tarafından yapılan $\mathrm{Ar}-\mathrm{Ge}$ harcamalarının GSYİH'ye oranını ülkeler bazında göstermektedir. BİT, servis ve imalat olarak ikiye bölündüğü zaman harcamaların daha ziyade BİT servis tarafından geldiği gözlemlenmektedir. Gelişmiş ülkelerin harcamalarda başı çektiği görülmekle beraber, Güney Kore, Tayvan ve Çin gibi gelişmekte olan ülkelerin de üst sıralarda yer aldığı görülmektedir. Türkiye ise yaklaşık $\% 0,5$ ile bu tabloda gerilerde kalmaktadır.

Bu çalıșmada, Türkiye'de Bilgi ve İletişim Teknolojileri Sektörü Ar-Ge harcamalarının gelișimi hakkında bilgi verilmiș, Ar-Ge harcamaları ve ekonomik büyüme arasındaki ilişki Granger nedensellik testi kullanılarak analiz edilmiştir. Dolayısıyla, Bilgi ve İletişim Teknolojileri sektörünün, sürdürülebilir ekonomik büyüme için önemi ortaya koyulmuştur.

Şekil 2. Dünyada BİT Sektörü Şirket Ar-Ge Harcamaları / GSYIH (\%), 2015

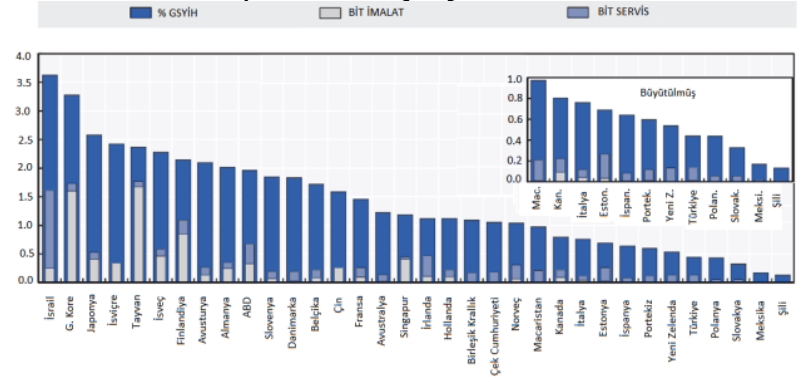

Kaynak: OECD, 2017.

\section{LITTERATÜR ÖZETI}

Telekomünikasyon yatırımlarının ekonomik büyüme üzerindeki etkisini hem yatay kesit hem de gelișmiş zaman serisi ekonometrisi kullanarak ölçen çok sayıda bilimsel çalışma bulunmaktadır (Wolde-Rufael, 2007). BİT yatırımları ile ekonomik büyüme arasındaki nedensellik ilişkisi üzerine ise tek ülke ve birçok ülkeyi örneklem olarak kullanan çalışmalar da literatürde mevcuttur.

Cronin vd. (1991), Amerika Birleşik Devletleri'nde BIT yatırımı ve ekonomik büyüme arasındaki nedensellik ilişkisini incelemiş ve telekomünikasyon yatırımlarının ekonomik aktivite büyümesini olumlu etkilediğini, ayrıca ekonomik aktivite ve büyümenin de telekomünikasyon altyapı yatırmalarına olan talebi canlandırdığını göstermiștir. Öte yandan, Beil vd. (2005), telekomünikasyon yatırımlarının ekonomik aktiviteden kaynaklandığını fakat ekonomik aktivitenin nedeni olmadığını belirtmiştir. $\mathrm{Bu}$ iki çalışmanın dışında tek bir ülkeyi örneklem olarak analiz eden birçok çalışma bulunmaktadır. Güney Kore'yi inceleyen Yoo ve Kwak (2004) ve Hindistan'ı analiz eden Veeramacheneni vd. (2008), BİT yatırımları ile ekonomik gelişme arasında iki yönlü bir nedensellik tespit etmiştir. Doğu Avrupa'daki 
ülkeleri örneklem olarak kullanan Dvorjnik ve Saboliç (2007), tek yönlü nedenselliğin BìT yatırımlarından ekonomik kalkınmaya doğru olduğunu göstermiştir. Buna karşıllık, Shiu ve Lam'ın (2008) Çin ve Sadr ve Yazdan'ın (2012) İran üzerine yaptığı araştırmalar, tek yönlü nedenselliğin ekonomik büyümeden, telekomünikasyon altyapısı kalkınması yönünde olduğunu ortaya koymuştur. Ayrıca, Japonya'nın BíT yatırımlarının ekonomik büyüme ve enerji tüketimi üzerindeki etkisiyle ilgili araştırma yapan Ishida (2015), BİT yatırımlarının enerji tüketiminde ılımlı bir düşüsse katkıda bulunabileceğini, ancak GSYH'nin artmasına katkıda bulunmadığını tespit etmiştir.

BİT yatırımları ile ekonomik büyüme arasındaki nedensellik ilişkisi üzerine birden fazla ülkede yapılan çalışmalar ise şöyledir; Dutta (2001), gelişmekte olan 15 ve gelişmiş 15 olmak üzere toplam 30 ülkede telekomünikasyon altyapısı ile ekonomik faaliyet arasındaki nedensellik ilişkisini incelemiştir. Çalışmanın sonuçları, telekomünikasyon altyapısı düzeylerinin ekonomik aktiviteye olan nedensellik ilişkisinin, ters yöndeki nedensellikten daha güçlü olduğunu göstermiștir. Veeramacheneni vd. (2007), Latin Amerika'da 10 ülkeyi kapsayan çalışmalarında, yedi ülke için BİT yatırımları ile ekonomik büyüme arasında iki yönlü bir nedensellik ilişskini tespit etmiştir. Bununla beraber, Pradhan vd. (2014) hem gelişmiş hem de gelişmekte olan G-20 ülkelerinde telekomünikasyon altyapısının gelişimi ile ekonomik büyüme arasında iki yönlü bir nedensellik ilişkisi olduğunu ortaya koymuştur.

Türkiye için özel olarak BíT Ar-Ge harcamaları ve BITT sektörü büyümesi arasındaki ilişkiyi inceleyen, bilindiği kadarıyla, çalışma bulunmamakla beraber, Ar-Ge harcamaları ile genel ekonomik büyüme arasındaki ilişkiyi inceleyen çok sayıda analiz literatürde yer almaktadır. Bu çalışmalar arasında Altın ve Kaya (2009), Yaylalı, Akan ve Işsk (2010), Korkmaz (2010), Taş, Taşar ve Açcl (2017) ekonomik büyüme ve Ar-Ge harcamaları arasında nedensellik ilişskisi olduğu sonucuna ulaşmıştır.

\section{VERİ SETİ ve YÖNTEM}

\subsection{Veri Seti}

Çalışmada örneklem olarak, BíT GSYIH ve BİT Ar-Ge harcamalarına ilişskin 2003-2017 yılları arası veriler kullanılmıștır. Veriler Türkiye İstatistik Kurumu'ndan (TÜIKK) edinilmiștir. Örneklemin başlangıç yılı 2003 yılıdır çünkü TÜİK, Ar-Ge harcamalarını ekonomik faaliyet kodu ayrımıyla bu yıl itibariyle paylaşmaktadır. Çalışmanın örneklemi Şekil 3 'te grafiksel olarak sunulmaktadır. Hem BİT sektörü hasılasında hem de BíT Ar-Ge harcamalarında paralel bir artış gözlenmektedir. Yani değişkenler yıllar içinde birbiri ile benzer hareketler göstermiștir.

Şekil 3. Bilgi ve İletişim Teknolojileri Sektörü GSYIH ve AR-GE Harcamaları

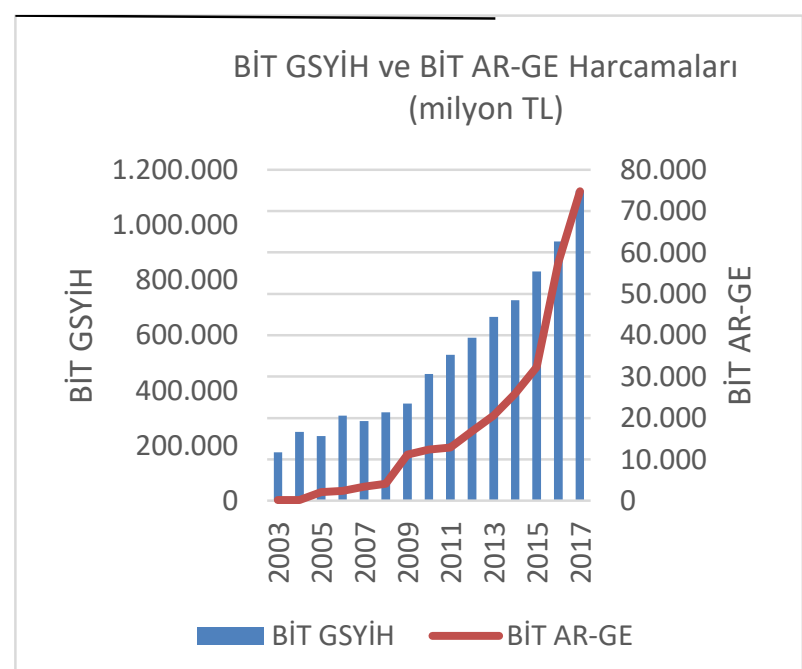

Kaynak: TÜİK, Ar-Ge İstatistikleri, 2019.

\subsection{Ekonometrik Yöntem}

Analiz edilen örneklem nispeten küçük bir örneklem ise, Guilkey ve Salemi (1982) ve Geweke ve ark. (1983), Granger nedensellik testlerinin diğer birçok yönteme göre daha güvenilir sonuçlar verdiğini belirlemiştir. $\mathrm{Bu}$ sebeple, çalışmada Hong (2017) takip edilerek ekonometrik yöntem olarak Granger nedensellik testi seçilmiştir. 


\section{B. PAKDEMIRLI}

Stock ve Watson (1989), durağan olmayan zaman serisi verilerinin sahte regresyona sebebiyet verebileceğini ortaya koymuştur. $\mathrm{Bu}$ problemden ötürü, ilk olarak verilerin durağanlık durumlarını belirlemek adına birim kök testleri yapılmıştır. Eğer değişkenler durağan değil ise, iki değişken arasında doğrusal bir kombinasyonun var olup olmadığını tespit etmek için eşbütünleşme testi uygulanmıştır. Son olarak, zaman serisi değişkenleri arasında bir eşbütünleşme var ise, vektör hata düzeltme modeli kullanılarak değişkenler arası Granger-nedensellik analiz edilmiştir.

\subsubsection{Birim Kök Testi}

Phillips-Perron (PP), Dickey-Fuller (DF) ve Genişletilmiş Dickey-Fuller (ADF) testleri literatürde birim kök tespiti için faydalanılan testlerdir. DF, düzeltme teriminin otokorelasyon ve değișen varyans içermediğini varsaymaktadır. Ayrıca, Schwert (1987), PP testinin zaman serilerinin durağan olmadığ olduğunu ve Davidson ve MacKinnon (2004) ise PP testinin ADF testinden özellikle küçük örneklemlerde daha başarısız olduğunu iddia etmesi sebebiyle bu çalışmada, ADF birim kök testi olarak kullanılmıştır.

Birim kök testlerinde yanlılığı azaltacak optimum bir gecikme uzunluğu seçilmelidir. Bunun için literatüre uyumlu olarak FPE (Final Prediction Error) (Akaike, 1969), AIC (Akaike, 1973), HQIC (Hannan-Qiunn Criterion) (Hannan ve Quinn, 1979) ve SIC (Schwarz, 1978) bilgi kriterlerinden yararlanılmıştır.

\subsubsection{Eşbütünleşme Testi}

Eğer iki zaman serisi durağan değilse ve aralarında doğrusal bir kombinasyon varsa, serilerin eşbütünleşmeye sahip olduğu söylenebilir. Eşbütünleşme testleri uzun vadeli ilişkileri regresyon analizinden daha doğru ve yansız bir biçimde test edebilmektedir.

Eşbütünleşme testleri, regresyon kalıntı-bazlı ve denklem-bazlı olarak ikiye ayrılabilir
(Hong, 2017). Gonzalo (1994), literatürde en sık kullanılan beş eşbütünleşme testini kıyaslamıș, Johansen ve Juselius'un (1988) ve Johansen (1988) önerdiği en yüksek olabilirlik metodunun en etkin metot olduğunu ortaya koymuştur. $\mathrm{Bu}$ sebepten, çalışmanın eşbütünleşme analizi kısmında denklem-bazlı olan Johansen eşbütünleşme testi kullanılmıștır.

Johansen eşbütünleşme testinde de yanlılığ azaltmak için optimum gecikmeler belirlenmelidir. Gecikmeleri belirlemek için yine bilgi kriterlerinden yararlanılmıștır.

\subsubsection{Vektör hata düzeltme modeli nedensellik analizi}

Değişkenler arasında eşbütünleșmenin varlığı neticesinde nedensellik analizi, bir hata düzeltme modeli yardımıla gerçekleştirilmelidir. Kısa dönem ve uzun dönem nedensellikleri, hata düzeltme modeli ile aynı anda tespit edilebilir. Zira bu model hem bağımsız değişkenlerin gecikme değerleri farklarının bağımlı değişken üstündeki etkilerini hem de hata düzeltme terimindeki değișikliklerin bağımlı değișkenler üstündeki etkilerini ortaya koyabilmektedir (Hong, 2017).

$$
\begin{aligned}
& \Delta Y_{t}=\alpha_{1}+\sum_{i=1}^{L_{11}} \beta_{11} \Delta Y_{t-i}+ \\
& \sum_{j=1}^{L_{12}} \beta_{12} \Delta X_{t-j}+\gamma_{1} \hat{\mathrm{e}}_{t-1}+\mu_{1 t} \\
& \Delta X_{t}=\alpha_{2}+\sum_{i=1}^{L_{21}} \beta_{21} \Delta Y_{t-i}+ \\
& \sum_{j=1}^{L_{22}} \beta_{22} \Delta X_{t-j}+\gamma_{2} \hat{\mathrm{e}}_{t-1}+\mu_{2 t}
\end{aligned}
$$

Eşitlik 1 ve Eşitlik 2, vektör hata düzeltme modeli (VECM) olarak tanımlanır. Eşitliklerde $\mathrm{L}$, optimal gecikme; $\hat{\mathrm{e}}_{t-1}$, hata düzeltme terimi ve $\mu_{t}$ ise hata terimidir. Eşitlik $1, \mathrm{X}$ bağımsız değişkeninden $\mathrm{Y}$ bağıml değişkenine olan nedenselliği kapsamaktadır. Eğer, $\beta_{12}$ anlamlı olarak sıfırdan farklı bulunursa, $\mathrm{X}$ bağımsız değişkeninden $\mathrm{Y}$ bağımlı değişkenine kısa dönemli Granger nedenselliğin varlığı geçerlidir. Eşitlikteki hata düzeltme teriminin katsayısı $\left(\gamma_{1}\right)$ dengeye doğru hareket etme hızını temsil eder. Eğer, $\gamma_{1}$ anlamlı olarak 
sıfırdan farklı bulunursa, $X$ bağımsız değişkeninden $\mathrm{Y}$ bağımlı değişkenine uzun dönemli Granger nedenselliği var demektir. Eşitlik 2 de ise $Y$ bağımsız değişkeninden $X$ bağımlı değişkenine olan nedensellik gösterilmektedir. $\beta_{22}$ ve $\gamma_{2}$ katsayları sırasıyla kısa dönemli ve uzun dönemli Granger nedenselliğin tespit edilmesinde kullanılır.

$\mathrm{Bu}$ modelde bağımsız değişkenlerin gecikme uzunluğu sonuçlara etki edeceğinden dolayı özenle belirlenmelidir. Bilgi kriterlerinden faydalanarak optimum gecikme uzunlukları seçilmiştir.

\section{AMPIRIKK BULGULAR}

\subsection{Birim Kök Testleri}

Tablo 1, BİT GSYİH ve BİT Ar-Ge harcamaları zaman serileri için ADF birim kök testlerinin sonuçlarını göstermektedir. Sonuçlar, BİT GSYIH ve Ar-Ge harcamalarının \%1 anlamlılık düzeyinde birim köke sahip olduğunu ortaya koymaktadır.

Tablo 1. Birim kök testi sonuçları

\begin{tabular}{|c|c|}
\hline & $\begin{array}{c}\text { Genişletilmiş Dickey- } \\
\text { Fuller }\end{array}$ \\
\hline BíT GSYİH & $-0.915^{*}$ \\
\hline BİT Ar-Ge Harcamaları & $-1.892^{*}$ \\
\hline
\end{tabular}

*: \%1 anlamlılık düzeyi

\subsection{Eşbütünleşme Testi}

Optimum gecikme uzunluğunu belirlemek için faydalanılan bilgi kriterlerinin sonuçları Tablo 2'de verilmektedir. Tabloya göre optimum gecikme uzunluğu 4 olarak seçilmelidir.

Tablo 2. Optimum gecikme uzunluğu

\begin{tabular}{|c|c|c|c|c|}
\hline $\begin{array}{c}\text { Gecikme } \\
\text { uzunluğu/Kriter }\end{array}$ & FPE & AIC & HQIC & SIC \\
\hline 1 & 0.000037 & $\begin{array}{c}- \\
4.57074 \\
\end{array}$ & $\begin{array}{c}- \\
4.70755 \\
\end{array}$ & $\begin{array}{c}- \\
4.35371 \\
\end{array}$ \\
\hline 2 & 0.000073 & $\begin{array}{c}- \\
3.99143 \\
\end{array}$ & $\begin{array}{c}- \\
4.21945 \\
\end{array}$ & $\begin{array}{c}- \\
3.62971 \\
\end{array}$ \\
\hline 3 & $\begin{array}{c}0.000021 \\
*\end{array}$ & $\begin{array}{c}- \\
5.55102 \\
\end{array}$ & $\begin{array}{c}- \\
5.87024 \\
\end{array}$ & $\begin{array}{c}- \\
5.04461 \\
\end{array}$ \\
\hline 4 & 0.000041 & $\begin{array}{c}- \\
5.77009 \\
* \\
\end{array}$ & $\begin{array}{c}- \\
6.18052 \\
*\end{array}$ & $\begin{array}{c}- \\
5.11899 \\
* \\
\end{array}$ \\
\hline
\end{tabular}

*: en düşük değer

Seçilen optimum gecikme uzunluğu ile gerçekleştirilen eşbütünleşme testinin sonuçları Tablo 3'te ortaya konmaktadır. Herhangi bir eşbütünleşmenin var olmadığını öne süren boş hipotez $\left(\mathrm{H}_{0}: \quad \mathrm{R}=0\right)$ reddedilmekte, en az bir eșbütünleşmenin var olduğunu öngören boş hipotez $\left(\mathrm{H}_{0}: \mathrm{R} \leq 1\right)$ ise reddedilememektedir. Yani sonuçlar bir eşbütünleşmenin var olduğunu göstermektedir.

Tablo 3. Johansen Eșbütünleşme

\begin{tabular}{|c|c|c|c|c|}
\hline Boş hipotez & $\begin{array}{c}\text { Maksimum } \\
\text { özdeğer } \\
\text { testi }\end{array}$ & $\begin{array}{c}\text { Maksimum } \\
\text { özdeğer } \\
\text { testi }\end{array}$ & İz testi & $\begin{array}{c}\text { İz } \\
\text { testi }\end{array}$ \\
\hline Rank & $\begin{array}{c}\text { Test } \\
\text { istatistiği }\end{array}$ & Kritik değer & $\begin{array}{c}\text { Test } \\
\text { istatistiği }\end{array}$ & $\begin{array}{c}\text { Kritik } \\
\text { değer }\end{array}$ \\
\hline$=0$ & $19.1970^{*}$ & 15.41 & $16.1294^{*}$ & 14.07 \\
\hline$\leq 1$ & 3.0376 & 3.76 & 3.0676 & 3.76 \\
\hline
\end{tabular}

*: \%5 anlamlılık düzeyi

\subsection{Vektör hata düzeltme modeli nedensellik analizi}

Tablo 4, dört gecikme uzunluğunu kapsayan VECM kullanılarak yapılan Granger nedensellik analizinin bulgularını göstermektedir.

Tablo 4. VECM-Granger nedensellik

\begin{tabular}{|c|c|c|c|}
\hline Boş hipotez & Test istatistiği & $\begin{array}{c}\text { Kisa } \\
\text { dönem } \\
\text { nedensellik }\end{array}$ & $\begin{array}{c}\text { Uzun } \\
\text { dönem } \\
\text { nedensellik }\end{array}$ \\
\hline \multirow{2}{*}{$\begin{array}{l}\text { Ar-Ge harcamaları, BİT } \\
\text { sektör hasılanın Granger } \\
\text { nedeni değildir. }\end{array}$} & F-istatistiği & $2.89^{*}$ & - \\
\hline & $\begin{array}{c}\text { Hata düzeltme } \\
\text { katsayısı }\end{array}$ & - & $-0.23^{*}$ \\
\hline \multirow{2}{*}{$\begin{array}{l}\text { BİT sektör hasılası, Ar-Ge } \\
\text { harcamalarının Granger } \\
\text { nedeni değildir. }\end{array}$} & F-istatistiği & 1.60 & - \\
\hline & $\begin{array}{c}\text { Hata düzeltme } \\
\text { katsayısı }\end{array}$ & - & $-4.27^{*}$ \\
\hline
\end{tabular}

Bulgular, BİT Ar-Ge harcamaları ve BİT sektörü hasılası arasında uzun dönemli nedensellik ilişkisi olduğunu belirtmektedir. BİT Ar-Ge harcamaları hata düzeltme teriminin katsayısı negatif ve istatistiksel olarak anlamlıdır, yani uzun dönemde BİT ArGe harcamaları BİT hasılasını pozitif olarak etkilemektedir. Ayrıca, BİT Ar-Ge harcamalarının BİT GSYİH'ye olan kısa dönem nedenselliğini temsil eden $F$ istatistiği de istatistiksel olarak anlamlıdır. BİT GSYİH hata düzeltme teriminin katsayısı da negatif ve istatistiksel olarak anlamlıdır. $\mathrm{Bu}$ da BİT sektörü hasılasının BİT Ar-Ge harcamalarını uzun dönemde olumlu olarak değiştirdiğini göstermektedir. Fakat kısa dönem nedensellik 


\section{B. PAKDEMIRLI}

bulgularına göre BİT sektörü hasılası BİT Ar$\mathrm{Ge}$ harcamalarının nedeni değildir. Öte yandan, Jarque-Bera normallik testi hata düzeltme modeli kalıntılarının normal olarak dağıldığını, modelde otokorelasyon ve değișen varyans problemleri var olmadığını ortaya koymaktadır.

\section{SONUÇ}

$\mathrm{Bu}$ çalışma, Türkiye BİT sektörü Ar-Ge harcamaları ile BİT sektör büyümesi arasındaki nedensellik ilişkisini incelemektedir. Nedensellik testlerinden önce, zaman serisi değișkenlerinin durağanlığını ölçmek için birim kök testleri uygulanmıştır. Birim kök testi bulgularına göre verilerin durağan olmadığı bulunmuştur. İki değişken arasında doğrusal kombinasyonun olup olmadığını belirlemek için eşbütünleşme analizi yapılmış ve değişkenler arası bir eşbütünleşme ilişkisi gözlenmiştir. Son olarak, zaman serileri arasında bir eşbütünleşme ilişkisi var olduğundan, değişkenler arası Granger-nedensellik, vektör hata düzeltme modeli yardımıyla test edilmiştir.

Türkiye'de kamu ve kamu dişı kurumlar tarafından yapılan BİT Ar-Ge harcamaları, 2003 yılından itibaren düzenli bir artış göstermektedir. Yanı sıra BİT hasılası da bu dönemde benzer bir artış yaşamıştır. Çalışmanın ekonometrik bulguları, BiT Ar-Ge harcamaları ile BİT hasılası arasında iki yönlü nedensellik olduğunu göstermektedir. Diğer bir deyişle, Ar-Ge harcamaları BİT sektörünün büyümesine, BİT sektörünün büyümesi de Ar$\mathrm{Ge}$ harcamalarının artışına yol açmaktadır. Çalışma bu yönüyle hem dünya örnekleri olan Cronin vd. (1991), Yoo ve Kwak (2004) ve Veeramacheneni (2008) araştırmaları hem de Türkiye örnekleri olan Altın ve Kaya (2009), Yaylalı, Akan ve Işık (2010), Korkmaz (2010), Taş, Taşar ve Açcı (2017) çalışmaları ile sonuçları itibariyle uyumluluk göstermektedir. Dolayısıyla, Türkiye ekonomisinde sürdürülebilir bir büyüme için BİT sektörü Ar-Ge harcamalarının hem kamu hem de özel sektör tarafından planlı bir biçimde artarak devam ettirilmesi gerekmektedir. Ar-Ge'ye verilen önem sayesinde teknolojinin etkin kullanımı ve yüksek teknoloji üretebilen yeni firmalar ortaya çlkar. Bu firmalar da bilgiyi teknolojik ürünlere dönüştürerek diğer sektörlere teknoloji transferinin zeminini hazırlarlar. ArGe ağırlıklı bu faaliyetler sayesinde ekonomik faaliyetler çeşitlenir, ekonomik verimlilik artar ve ekonomi gelişme sağlar (Yaylalı, Akan, Isık, 2010).

Çalışmanın örneklemi, nispeten kısa bir dönem olan 2003-2017 yılları arası verilerden oluşmaktadır. Çalışmanın bulguları istatistiksel olarak anlamlıdır fakat gelecekte yapılacak daha büyük örneklem kullanan çalışmalar, bu çalışmanın kısıtlı örneklem sonuçlarını destekleyecektir.

\section{REFERANSLAR}

Akaike, H., 1969. Fitting autoregressive models for prediction. Annals of the Institute of Statistical Mathematics, 21: 243-247.

Akaike, H., 1973. Information theory and an extension of the maximum likelihood principle. 2nd International Symposium on Information Theory by B.N. Petrov and F. Csaki (Eds.), Akademiai Kiado: Budapest.

Altın, O., ve Kaya, A. (2009). Türkiye'de Ar-Ge Harcamaları ve Ekonomik Büyüme Arasındaki Nedensel İlişkinin Analizi. Ege Akademik Bakış, 9(1).
Anonim. (2019). TÜİK, AraştırmaGeliştirme Faaliyetleri Araştırması, Ar-Ge İstatistikleri. Erişim Adresi http://www.tuik.gov.tr/.

Beil, R. O., Ford, G. S., ve Jackson, J. D. (2005). On the relationship between telecommunications investment and economic growth in the United States. International Economic Journal, 19(1), 3-9.

Cronin, F. J., Parker, E. B., Colleran, E. K., ve Gold, M. A. (1991). Telecommunications 
infrastructure and economic growth: An analysis of causality. Telecommunications Policy, 15(6), 529-535.

Davidson, R., MacKinnon, J.G., 2004. Econometric Theory and Methods (Vol. 5). New York: Oxford University Press.

Dutta, A., 2001. Telecommunications and economic activity: an analysis of granger causality. J. Manag. Inf. Syst. 17 (4), 71-95.

Dvornik, D., ve Sabolić, D. (2007). Telecommunication liberalization and economic development in European countries in transition. Technology in Society, 29(4), 378-387.

Geweke, J., Meese, R., Dent, W., 1983. Comparing alternative tests of causality in temporal systems: analytic results and experimental evidence. Journal of Econometrics, 21(2): 161-194.

Gonzalo, J., 1994. Five alternative methods of estimating long-run equilibrium relationships. Journal of Econometrics, 60(12): 203-233.

Guilkey, D.K., Salemi, M.K., 1982. Small sample properties of three tests for Grangercausal ordering in a bivariate stochastic system. The Review of Economics and Statistics, 668-680.

Hannan, E.J., Quinn, B.G., 1979. The determination of the order of an autoregression. Journal of the Royal Statistical Society: Series B (Methodological), 41(2): 190195.

Hong, J.P., 2017. Causal relationship between ICT R\&D investment and economic growth in Korea. Technological Forecasting and Social Change, 116, pp.70-75.

Ishida, H. (2015). The effect of ICT development on economic growth and energy consumption in Japan. Telematics and Informatics, 32(1), 79-88.

Johansen, S., 1988. Statistical analysis of cointegration vectors. Journal of Economic Dynamics and Control, 12(2-3): 231-254.
Johansen, S., Juselius, K., 1988. Hypothesis testing for cointegration vectors: With application to the demand for money in Denmark and Finland. Discussion Paper 8805. University of Copenhagen, Copenhagen.

Kocamış, T. U., ve Güngör, A. (2014). Türkiye'de Ar-Ge Harcamaları ve Teknoloji Sektöründe Ar-Ge Giderlerinin Kârlılık Üzerine Etkisi: Borsa İstanbul Uygulaması. Maliye Dergisi, 166, 127-138.

Korkmaz, S. (2010). Türkiye'de Ar-Ge Yatırımları ve Ekonomik Büyüme Arasındaki İlişkinin VAR Modeli ile Analizi. Journal of Yasar University, 20(5), 3320-3330.

OECD. (2015). Frascati Manual 2015: Guidelines for Collecting and Reporting Data on Research and Experimental Development, The Measurement of Scientific, Technological and Innovation Activities, Paris, OECD Publishing, DOI: http://dx.doi.org/10.1787/9789264239012en.

OECD. (2017). OECD Digital Economy Outlook 2017. Paris: OECD. Erișim Adresi http://dx.doi.org/10.1787/9789264276284en.

Pradhan, R. P., Arvin, M. B., Norman, N. R., ve Bele, S. K. (2014). Economic growth and the development of telecommunications infrastructure in the G-20 countries: A panelVAR approach. Telecommunications Policy, 38(7), 634-649.

Sadr, H. M. S., ve Yazdan, F. G. (2012). Consideration the causality between information and communication technology and economic growth in Iran. J. Econ. Sustain. Dev, 3(6), 86-92.

Schwarz, G., 1978. Estimating the dimension of a model. Annals of Statistics, 6: 461-464.

Schwert, G.W., 1987. Effects of model specification on tests for unit roots in macroeconomic data.Journal of Monetary Economics, 20(1): 73-103. 


\section{B. PAKDEMÍRLI}

Shiu, A., ve Lam, P. L. (2008). Causal relationship between telecommunications and economic growth in China and its regions. Regional Studies, 42(5), 705-718.

Stock, J.H., Watson, M.W., 1989. Interpreting the evidence on money-income causality. Journal of Econometrics, 40(1): 161181.

Taş, Ş., Taşar, İ., ve Açcl, Y. (2017). AR-GE Harcamaları ve Ekonomik Büyüme Arasındaki İlişki: Türkiye Örneği.Ömer Halisdemir Üniversitesi Íktisadi ve İdari Bilimler Fakültesi Dergisi, 10(2), 178-187.

Wolde-Rufael, Y. (2007). Another look at the relationship between telecommunications investment and economic activity in the United States. International Economic Journal, 21(2), 199-205.

Veeramacheneni, B., Ekanayake, E. M., ve Vogel, R. (2007). Information technology and economic growth: A causal analysis. Southwestern Economic Review, 34, 75-88.

Veeramacheneni, B., Vogel, R., ve Ekanayake, E. M. (2008). Information Technology, FDI and Economic Growth: An India Case Study. Southwestern Economic Review, 35, 95-111.

Yaylalı, M., Y., Akan., ve C., Işık (2010). Türkiye'de Ar\&Ge Yatırım Harcamaları ve Ekonomik Büyüme Arasındaki Eş-Bütünleşme ve Nedensellik İlişkisi: 1990-2009. Bilgi Ekonomisi ve Yönetimi Dergisi, 5(2).

Yoo, S. H., ve Kwak, S. J. (2004). Information technology and economic development in Korea: a causality study. International Journal of Technology Management, 27(1), 57-67. 